\title{
An Underdiagnosed Cause of an Itchy Back
}

\author{
Hiroaki Nakagawa $^{1}$ and Yasushi Miyata ${ }^{2}$
}

Key words: notalgia paresthetica, neuropathic itch, entrapment neuropathy

(Intern Med 60: 1983, 2021)

(DOI: 10.2169/internalmedicine.6481-20)

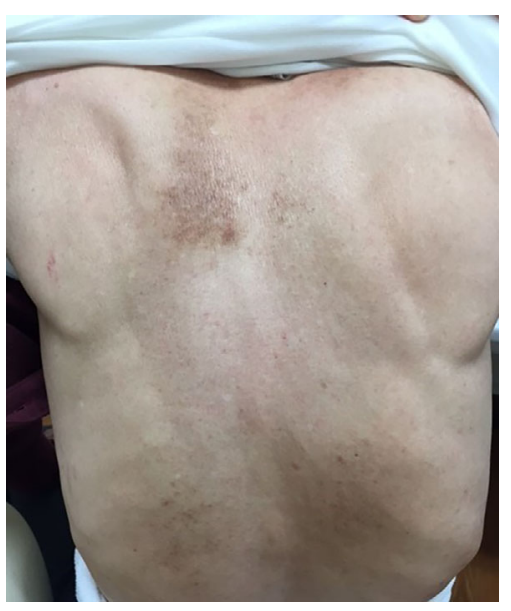

Picture.

A 74-year-old man presented with a 1-year history of an unexplained intermittent itch and stabbing pain on his upper back, medial to his left scapula. On an examination, scratching scars and hyperpigmentation were observed in the area (Picture), accompanied by hypoesthesia, without signs of inflammation. Notalgia paresthetica was diagnosed based on these findings. His symptoms resolved after treatment with capsaicin ointment. Notalgia paresthetica is an entrapment neuropathy caused by compression of the 2nd to 6th thoracic rami of the posterior root of the spinal nerve due to degeneration of the spine or intervertebral discs, extended bedridden periods, or muscular compression $(1,2)$. Symptoms are itching, paresthesia and stinging/burning pain of the upper back. Pigmentation is present in one-third of patients (2). Treatments include gabapentin, capsaicin ointment and stretching exercises $(1,2)$. Antihistamines and topical steroids are ineffective (1). The differential diagnosis includes postherpetic neuralgia and contact dermatitis. Appropriate treatment can improve the patient's quality of life.

The authors state that they have no Conflict of Interest (COI).

\section{References}

1. Šitum M, Kolić M, Franceschi N, Pećina M. Notalgia paresthetica. Acta Clin Croat 57: 721-725, 2018.

2. Howard M, Sahhar L, Andrews F, Bergman R, Gin D. Notalgia paresthetica: a review for dermatologists. Int J Dermatol 57: 388$392,2018$.

The Internal Medicine is an Open Access journal distributed under the Creative Commons Attribution-NonCommercial-NoDerivatives 4.0 International License. To view the details of this license, please visit (https://creativecommons.org/licenses/ by-nc-nd/4.0/).

\footnotetext{
${ }^{1}$ Division of General Medicine, Aichi Medical University, Japan and ${ }^{2}$ Department of Primary Care and Community Health, Aichi Medical University, Japan

Received: October 12, 2020; Accepted: December 7, 2020; Advance Publication by J-STAGE: February 1, 2021

Correspondence to Dr. Yasushi Miyata, ymymiyata@gmail.com
}

(C) 2021 The Japanese Society of Internal Medicine. Intern Med 60: 1983, 2021 